\title{
DESEMPENHO OPERACIONAL DE UMA SERRARIA DE PEQUENO PORTE DO MUNICÍPIO DE ALEGRE, ESPÍRITO SANTO, BRASIL
}

\author{
Djeison Cesar Batista ${ }^{1 *}$, João Gabriel Missia da Silva ${ }^{2}$, Wendel Sandro de Paula Andrade ${ }^{1}$, \\ Graziela Baptista Vidaurre ${ }^{1}$ \\ 1*Universidade Federal do Espírito Santo, Departamento de Ciências Florestais e da Madeira, Jerônimo Monteiro, Espírito Santo, \\ Brasil - djeison.batista@ufes.br; wendelandrade@hotmail.com; grazividaurre@gmail.com \\ ${ }^{2}$ Universidade Federal do Espírito Santo, Programa de Pós-Graduação em Ciências Florestais, Jerônimo Monteiro, Espírito Santo, \\ Brasil - j.gabrielmissia@hotmail.com.
}

Recebido para publicação: 22/11/2013 - Aceito para publicação: 10/03/2015

\begin{abstract}
Resumo
As serrarias são as principais indústrias madeireiras do sul do estado do Espírito Santo. O objetivo deste trabalho foi analisar o desempenho operacional de uma serraria de pequeno porte processadora da madeira de Eucalyptus sp. no município de Alegre, região sul do estado do Espírito Santo. Para tanto, a análise consistiu do estudo do rendimento em madeira serrada, eficiência operacional e amostragem do trabalho. O rendimento médio foi igual a 53,6\% e foi considerado bom, para uma serraria que processa madeira de folhosas, quando comparado com dados da literatura. A eficiência operacional média foi igual a $2,77 \mathrm{~m}$ \%operário/dia, e foi considerada baixa, mesmo para serrarias brasileiras de pequeno porte, em consequência da falta de classificação da matéria-prima, inadequações de layout, mau estado de conservação do maquinário e baixo nível de automação. $\mathrm{O}$ trabalho produtivo médio foi de $69,6 \%$ e não atingiu o valor mínimo de $75 \%$ sugerido pela literatura, resultado dos problemas referidos, dentre outros fatores. De uma maneira geral, o desempenho operacional da serraria foi considerado ruim, de acordo com os índices avaliados, porém possui potencial para ser melhorado.

Palavras-chave: Desdobro; rendimento em madeira serrada; eficiência operacional; trabalho produtivo.
\end{abstract}

\begin{abstract}
Operational performance of a small sawmill of the city of Alegre, Espirito Santo, Brazil. Sawmills are the most important wood industries in the Southern of the Espírito Santo State. The aim of this research was to analyze the operational performance of a small sawmill in Alegre, Espírito Santo state, Brazil, which process Eucalyptus sp. logs. The analysis was based on the study of lumber yield, operational efficiency and work delay ratio. The average lumber yield was $53.6 \%$ ranked as good for a small log hardwood sawmill, according to the literature. The average operational efficiency was $2.77 \mathrm{~m}$ /worker/shift, and was ranked as low, even for small Brazilian sawmills, due to not classified logs, layout inadequacies, machinery bad conservation and low automation level. The average productive work was $69.6 \%$ and did not achieve the minimum rank of $75 \%$ suggested by the literature, because of the referred problems, and other ones. In general, for such sawmill the operational situation was considered poor, but it has potential to be improved.

Keywords: Log breakdown; lumber yield; operational efficiency; productive work.
\end{abstract}

\section{INTRODUÇÃO}

O setor florestal no estado do Espírito Santo mobiliza cerca de $\mathrm{R} \$ 5$ bilhões, o que corresponde a $25 \%$ do PIB do agronegócio estadual, gera cerca de 80 mil empregos diretos e indiretos e envolve cerca de 28 mil propriedades rurais, como fomentados ou produtores independentes (CENTRO DE DESENVOLVIMENTO DO AGRONEGÓCIO (CEDAGRO), 2011). Nesse setor, o segmento de serrarias possui uma importante contribuição socioeconômica, gerando empregos e renda nas economias regionais.

FLORESTA, Curitiba, PR, v. 45, n. 3, p. 487 - 496, jul. / set. 2015.

Batista, D. C. et al.

ISSN eletrônico 1982-4688 / ISSN impresso 0015-3826

DOI: $10.5380 /$ rf.v45i3.34441 
As microrregiões do Caparaó e Polo Cachoeiro, no sul capixaba, possuem aproximadamente 60 serrarias de pequeno porte (18,2\% do total do estado), com uma produção anual de $195.375 \mathrm{~m}^{3}$ de madeira serrada. Como a maioria desses empreendimentos é de origem familiar, o número de funcionários é variável de acordo com a estrutura, nível tecnológico e produtos processados, sendo uma média de empregos/ocupações igual a 13,6 pessoas/serraria (CEDAGRO, 2011).

Essas serrarias, como as demais empresas nacionais desse porte, não possuem informações precisas do desempenho operacional da sua produção. Tal carência técnica é impeditiva ao desenvolvimento dos empreendimentos, porque a gerência não possui subsídios que orientem a administração e o planejamento da produção e informem sobre os investimentos necessários e ocorrência de desperdícios dos recursos financeiros e técnicos. Em virtude da importância socioeconômica das pequenas serrarias, há a necessidade de um diagnóstico da situação operacional desses empreendimentos, possibilitando o conhecimento de como e quando realizar a reestruturação interna das empresas, ajustes nas operações produtivas e investimento no treinamento e qualificação da mão de obra. Isso contribui para o uso racional da matéria-prima, tornando-as mais eficientes e competitivas no mercado interno.

Como ferramentas de análise do desempenho de uma serraria de pequeno porte no estado do Rio de Janeiro, Batista e Carvalho (2007) utilizaram o rendimento em madeira serrada, a eficiência operacional e o método da amostragem do trabalho. Dessa forma, os autores conseguiram diagnosticar a situação operacional da serraria, apresentando os principais problemas observados na linha de produção e propondo sugestões de melhorias e solução dessas limitações.

O rendimento em madeira serrada é a relação entre o volume de toras desdobradas num período ou turno e o volume de madeira serrada produzido das respectivas toras. Considera-se normal uma amplitude de rendimento em madeira serrada entre 45 e $65 \%$, variável de acordo com a espécie utilizada (ROCHA, 2002). Os fatores que influenciam no rendimento em madeira serrada, no entanto, vão além das características da madeira e da qualidade de toras, pois incluem a mão de obra, maquinário utilizado, nível de automação, sistema de desdobro, modelos de corte e o produto (dimensões das peças serradas).

A eficiểncia operacional expressa a relação entre o volume de toras desdobradas por período ou turno e o número de operários envolvidos em todas as operações de desdobro (ROCHA, 2002). Segundo Latorraca (2004), em serrarias de pequeno e médio porte, em que o grau de automação é baixo, a noção da eficiência técnica é importante para a organização produtiva, pois informa com segurança como o trabalho ou o desdobro está sendo conduzido ao longo do turno avaliado.

A amostragem do trabalho é uma técnica estatística que foi desenvolvida com o propósito específico de possibilitar a coleta de informações precisas com relação ao modo pelo qual as atividades são distribuídas em um dia de trabalho (NORDSTROM, 1962). A principal função dessa técnica é a análise do trabalho produtivo, por observação direta, em intervalos de tempo aleatórios ou sistemáticos.

A amostragem do trabalho para a avaliação de serrarias é dividida em trabalho produtivo e tempo perdido. $\mathrm{O}$ trabalho produtivo é o complemento entre homem e máquina que resulta na produção de madeira serrada, ao passo que o tempo perdido é caracterizado pelas situações em que esse conjunto não realiza as suas funções intrínsecas. O tempo perdido ainda se subdivide em trabalho não produtivo, tempo ocioso e demoras (LATORRACA, 2004).

O trabalho não produtivo é definido como as atividades do conjunto homem e máquina diferentes da produção de madeira serrada. Abreu et al. (2005) citaram como exemplos de trabalho não produtivo o posicionamento da tora no carro porta-toras, troca de lâminas e ajuste na guia da serra de fita. O tempo ocioso é classificado como a falta no abastecimento de energia, de matéria-prima e de insumos para as operações, bem como as necessidades pessoais dos operadores. As demoras ocorrem como resultado da má operação do sistema. Batista e Carvalho (2007) mencionaram alguns exemplos de situações caracterizadas como demoras, que incluem o manuseio da tora na rampa de abastecimento, o empilhamento de madeira serrada, a limpeza de subprodutos na linha de produção e as pausas na máquina primária por causa do abastecimento de toras com diâmetro maior que o comportado pela mesma.

O objetivo do trabalho foi analisar o desempenho operacional de uma serraria de pequeno porte no município de Alegre, região sul do estado do Espírito Santo, com base na avaliação do rendimento em madeira serrada, eficiência operacional e trabalho produtivo.

\section{MATERIAL E MÉTODOS}

\section{Caracterização da serraria}

A coleta de dados foi realizada em julho de 2010, em uma serraria localizada no distrito de Celina, município de Alegre, sul do estado do Espírito Santo, classificada como de pequeno porte, de 
acordo com critérios propostos por Rocha (2002), pois processava menos de $50 \mathrm{~m}^{3}$ de toras por dia. A empresa possuía uma linha de produção na qual trabalhavam nove operários e processava principalmente a madeira de Eucalyptus sp. oriunda de diversas localidades, adquirida de produtores florestais da região.

A linha de produção da serraria era equipada com uma serra de fita vertical simples (máquina primária), composta por um carro porta-toras manual e cinco serras circulares simples, utilizadas nas operações de desdobro secundário.

O principal produto da serraria era o "pré-cortado", que são ripas, de acordo com a Norma Brasileira Regulamentadora (NBR) 14807:2002 (ASSOCIAÇÃO BRASILEIRA DE NORMAS TÉCNICAS (ABNT), 2002), com dimensões de $20 \mathrm{~mm}$ de espessura x $30 \mathrm{~mm}$ de largura e comprimento variável, utilizadas na composição estrutural de estofados.

\section{Rendimento em madeira serrada}

Durante a realização do estudo do rendimento em madeira serrada, a empresa estava produzindo peças com as dimensões de $60 \mathrm{~mm}$ de espessura x $200 \mathrm{~mm}$ de largura x $3.600 \mathrm{~mm}$ de comprimento, que, de acordo com a NBR 14807:2002 (ABNT, 2002), são classificadas como pranchas. Essas peças foram produzidas sob encomenda, para utilização na montagem de tabuleiros de pontes. As toras foram desdobradas longitudinalmente, com a execução de cortes tangenciais em uma serra de fita vertical simples, conforme o modelo de corte apresentado na figura 1.
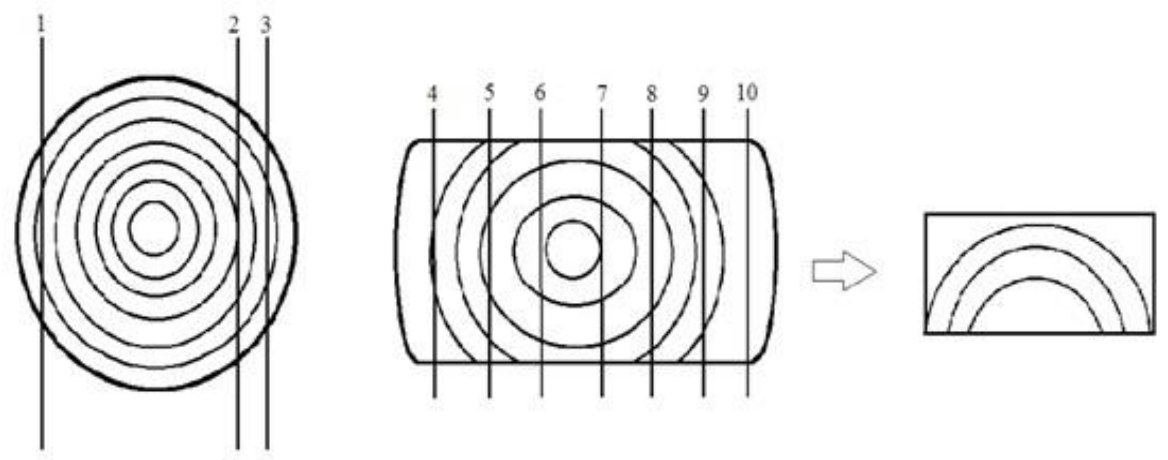

Figura 1. Modelo de corte utilizado pela serraria para obtenção das pranchas - estudo do rendimento em madeira serrada.

Figure 1. Sawing diagram for planks production - study of lumber yield.

Para o estudo do rendimento em madeira serrada, foram utilizadas 50 toras de Eucalyptus sp., representativas (amplitude do diâmetro de 25 a $30 \mathrm{~cm}$ ) do estoque do pátio, em que se determinou o volume sem casca, de acordo com a equação de Smalian. A empresa não realiza o descascamento, e as toras que foram amostradas tiveram apenas os extremos descascados manualmente $(10 \mathrm{~cm}$ de comprimento).

$$
\mathrm{Vt}=\frac{\pi}{80.000} \times\left(\mathrm{D}_{1}^{2}+\mathrm{D}_{2}^{2}\right) \times \mathrm{L}
$$

em que: $\mathrm{Vt}=$ volume sem casca da tora $\left(\mathrm{m}^{3}\right)$; D1 e D2 = diâmetros sem casca das extremidades da tora $(\mathrm{cm}) ; \mathrm{L}=$ comprimento da tora $(\mathrm{m})$.

Depois de identificadas e medidas, as toras foram encaminhadas para o desdobro na máquina primária. As pranchas originadas de cada tora foram devidamente identificadas com o respectivo número da tora e empilhadas separadamente. Posteriormente, calculou-se o volume de madeira serrada de cada peça (Equação 2), sendo o volume total de madeira serrada (Equação 3) de cada tora obtido pela soma do volume de cada peça gerada.

$$
\mathrm{Vp}=1 \times \mathrm{b} \times \mathrm{e}
$$

em que: $V p=$ volume da peça $\left(m^{3}\right) ; 1=$ comprimento da peça $(m) ; b=$ largura da peça $(m) ; e=$ espessura da peça $(\mathrm{m})$. 


$$
\mathrm{V}_{\mathrm{ms}}=\sum_{\mathrm{i}=1}^{\mathrm{n}} \mathrm{Vpi}
$$

em que: $\mathrm{V}_{\mathrm{ms}}=$ volume de madeira serrada $\left(\mathrm{m}^{3}\right) ; \mathrm{Vpi}=$ volume da peça $\mathrm{i}\left(\mathrm{m}^{3}\right)$. (2002).

O rendimento em madeira serrada foi calculado de acordo com a Equação 4, adaptada de Rocha

$$
\mathrm{R}_{\mathrm{ms}}=\left(\frac{\mathrm{V}_{\mathrm{ms}}}{\mathrm{Vt}}\right) \times 100
$$

em que: $\mathrm{R}_{\mathrm{ms}}=$ rendimento em madeira serrada $(\%) ; \mathrm{V}_{\mathrm{ms}}=$ volume de madeira serrada $\left(\mathrm{m}^{3}\right) ; \mathrm{Vt}=$ volume sem casca da tora $\left(\mathrm{m}^{3}\right)$.

\section{Método da amostragem do trabalho}

O método da amostragem do trabalho foi a técnica empregada para quantificar e analisar o trabalho produtivo nas operações desempenhadas pelo conjunto homem e máquina da serraria. Essa técnica foi escolhida por causa da confiabilidade estatística e por ter sido bem sucedida na avaliação operacional de serrarias (ABREU et al., 2005; BATISTA; CARVALHO, 2007; BATISTA et al., 2013).

Durante o estudo da amostragem do trabalho, foi avaliado o produto principal da serraria, o "précortado". As toras foram desdobradas longitudinalmente em uma serra de fita vertical simples e, em seguida, foram utilizadas três serras circulares simples, conforme o modelo de corte demonstrado na figura 2.
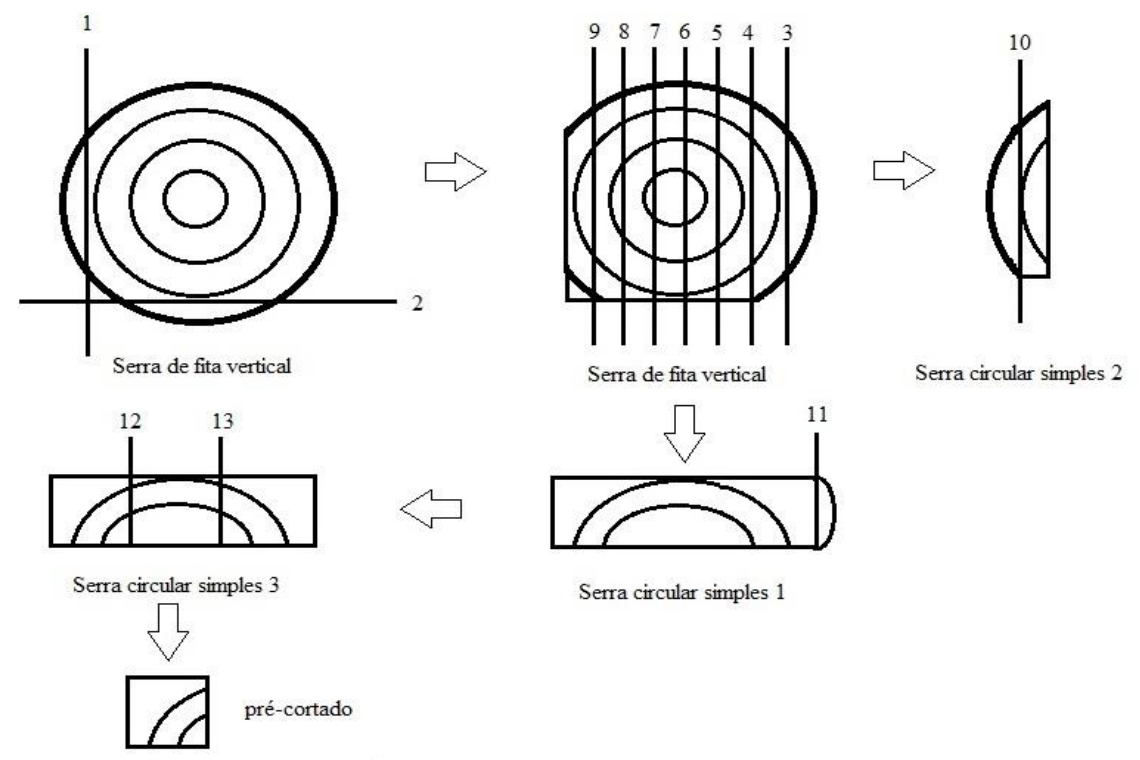

Serra circular simples 1

Figura 2. Modelo de corte utilizado pela serraria para obtenção do "pré-cortado" - método da amostragem do trabalho.

Figure 2. Sawing diagram for "pré-cortado" production - work delay ratio.

Segundo Batista e Carvalho (2007), uma etapa necessária para se estimar as proporções de tempo gasto em atividades específicas nunca examinadas em uma determinada serraria é a amostragem piloto. Com o levantamento das proporções, é possível calcular o número real de amostras a serem observadas durante o estudo do trabalho produtivo. A amostragem piloto foi realizada no turno 1 (período da manhã) do primeiro dia de avaliações, na qual foram feitas observações de dois em dois minutos (ABREU et al., 2005), durante 240 minutos, totalizando 120 observações diretas da linha de produção, classificadas apenas em trabalho produtivo e tempo perdido. 
Deve-se utilizar o valor da proporção de trabalho produtivo (P) obtido na amostragem piloto para a determinação do número real de amostras $(\mathrm{N})$ que devem ser avaliadas na linha de produção da serraria (BATISTA; CARVALHO, 2007). Para isso, as atividades classificadas como trabalho produtivo durante a amostragem piloto foram quantificadas e divididas pelo número total de observações, de acordo com a Equação 5.

$$
\mathrm{P}=\frac{\mathrm{n}}{\mathrm{N}}
$$

em que: $\mathrm{P}=$ proporção de trabalho produtivo; $\mathrm{n}$ = número de observações de trabalho produtivo;

$\mathrm{N}=$ número total de observações da amostragem piloto (120).

O número real de amostras a serem observadas na linha de produção foi calculado pela Equação 6 (STEVENSON, 2001).

$$
\mathrm{N}=\frac{\left[(\mathrm{Z})^{2} \times \mathrm{P} \times \mathrm{Q}\right]}{\mathrm{e}^{2}}
$$

em que: $\mathrm{N}=$ número real de amostras; $\mathrm{Z}=$ desvio normal padrão para o nível de confiança desejado; $\mathrm{P}=$ proporção de trabalho produtivo determinada na amostragem piloto; $\mathrm{Q}=1-\mathrm{P} ; \mathrm{e}=$ erro máximo por nível de precisão.

Adotou-se o nível de confiança de 5\% e erro máximo de $\pm 4 \%$ (MARTINS; LAUGENI, 2005; STEVENSON, 2001). De acordo com a área subentendida pela curva normal reduzida de 0 a Z, o desvio normal padrão para 95\% de probabilidade e 5\% de nível de confiança foi igual a 1,96.

Após o cálculo do número real de amostras, procedeu-se à coleta das observações, que revelou o quanto de trabalho produtivo e tempo perdido foi notado na linha de produção da serraria. Os dados foram quantificados em forma de porcentagem, de acordo com a classificação das atividades, tendo por base o número total de amostras observadas $(\mathrm{N})$.

\section{Eficiência operacional}

A determinação da eficiência operacional foi realizada durante o estudo da amostragem do trabalho, na produção do "pré-cortado". A eficiência operacional da serraria foi calculada de acordo com a Equação 7, adaptada de Rocha (2002).

$$
E=\frac{T}{O P}
$$

em que: $\mathrm{E}=$ eficiência operacional $\left(\mathrm{m}^{3}\right.$ /operário/dia); $\mathrm{T}=$ volume médio sem casca das toras desdobradas por dia $\left(\mathrm{m}^{3}\right) ; \mathrm{OP}=$ número de operários envolvidos nas operações de desdobro.

\section{RESULTADOS E DISCUSSÃO}

\section{Rendimento em madeira serrada}

As 50 toras de Eucalyptus sp. utilizadas no estudo do rendimento em madeira serrada apresentaram comprimento médio de 3,6 metros, diâmetro médio da extremidade menor de $26,1 \mathrm{~cm} \mathrm{e}$ $31,9 \mathrm{~cm}$ para a extremidade maior.

A média de rendimento em madeira serrada da serraria foi de 53,6\% (coeficiente de variação igual a $17,7 \%$ ) e está próxima do limite superior da amplitude de 45 a $55 \%$ dessa variável, considerada normal pela literatura para madeira de folhosas (ROCHA, 2002). Ressalte-se que esse resultado ocorreu porque todo o desdobro foi realizado em serra de fita vertical simples (que possui lâmina de pequena espessura de corte), eliminando o conceito de desdobro primário e secundário, e pelo fato de o produto final gerado possuir grandes dimensões (pranchas), não sendo realizados muitos cortes internos nas toras e semiblocos, conforme a figura 1 . Considerando o rendimento médio de 53,6\%, para a produção de um metro cúbico de pranchas, seria necessário o consumo de 1,86567 $\mathrm{m}^{3}$ de toras de Eucalyptus sp.

Espera-se que o rendimento da serraria seja menor durante a produção do "pré-cortado" (principal produto da empresa), por causa de dois fatores, principalmente: i) pequenas dimensões do 
produto, o que demanda a execução de maior quantidade de cortes nas toras; ii) como o modelo de corte do "pré-cortado" é diferente, é necessária a utilização de serras circulares no desdobro secundário, o que não ocorre na produção dos pranchões. Como essas máquinas possuem ferramentas de corte (discos denteados) com espessura de corte maior do que a lâmina denteada da serra de fita vertical simples, a produção de serragem é maior, o que diminui o rendimento.

O rendimento médio em pranchas da serraria foi superior aos rendimentos de 45,7\% para tábuas de Eucalyptus grandis Hill ex Maiden e de 41,3\% para tábuas de Eucalyptus dunnii Maiden (ROCHA, 2000). Essa diferença evidencia o efeito do tipo de produto gerado e do maquinário utilizado no rendimento em madeira serrada, em que o número de cortes utilizados para obter as tábuas é maior que o necessário para a geração das pranchas; e também o uso de serra circular múltipla de dois eixos durante a resserragem dos blocos de Eucalyptus grandis e Eucalyptus dunnii, que gera um volume significativo de serragem por causa da maior espessura de corte e, consequentemente, menor volume de madeira serrada por tora.

Considerando ainda o efeito do produto, foi realizada a comparação com outros três trabalhos que também avaliaram o rendimento na produção de tábuas. $\mathrm{O}$ rendimento médio foi superior aos $42,5 \%$ para Eucalyptus urophylla (SCANAVACA JÚNIOR; GARCIA, 2003), aos 38,6\% para um clone de híbridos naturais de Eucalyptus urophylla x Eucalyptus camaldulensis (SOUZA et al., 2007) e aos 44,9\% para Eucalyptus sp. (BATISTA; CARVALHO, 2007).

\section{Eficiência operacional}

Durante o período de estudo, foi observado que a serraria processava em média até 61 toras por dia (nove horas de trabalho), correspondente a um volume médio de $24,9 \mathrm{~m}^{3}$ de toras/dia, o que resulta em $13,4 \mathrm{~m}^{3} /$ dia de madeira serrada, considerando-se o rendimento médio de 53,6\%. Dividindo-se o volume médio de toras que é processado por dia pelo número de operários (nove), foi determinada uma eficiência operacional média de $2,77 \mathrm{~m}^{3}$ /operário/dia.

A baixa eficiência operacional da serraria avaliada está associada a limitações em seu layout, estado de conservação do maquinário de desdobro e baixo treinamento da mão de obra. Todas essas variáveis contribuíram para perdas no tempo da produção, influenciando diretamente o volume de toras desdobrado por dia por funcionário.

Nesse contexto, as restrições do layout estão relacionadas principalmente à má disposição do maquinário e à movimentação das toras, da madeira serrada e dos subprodutos na linha de produção, que é realizada de forma manual pelos operários. Além disso, o maquinário antigo e sem manutenção preventiva apresentou uma incidência de paradas no funcionamento por avarias e defeitos, além da sequência de recuo morto (retorno) do carro porta-toras. Já o baixo nível de treinamento da mão de obra contribuiu para o aumento do tempo de desdobro, por causa da fixação e giro das toras e erros na tomada de decisões de como efetuar os cortes, visando ao máximo aproveitamento da tora.

Batista et al. (2013) utilizaram a eficiência operacional para avaliar o desempenho no desdobro da madeira de Eucalyptus sp. de uma serraria de pequeno porte em Dores do Rio Preto, mesma região deste trabalho. Os autores obtiveram uma eficiência operacional de $5,06 \mathrm{~m}^{3} /$ operário/dia, superior à observada para a serraria de Alegre. A discrepância entre os resultados está relacionada principalmente a diferenças na movimentação das toras, capacidade produtiva dos maquinários utilizados e número de operários da linha de produção nas serrarias consideradas.

A eficiência operacional obtida foi inferior à média de $4,96 \mathrm{~m}^{3} /$ operário/dia obtida por Batista $\mathrm{e}$ Carvalho (2007), que estudaram uma serraria de pequeno porte no processamento da madeira de Eucalyptus sp., e ao valor mínimo de 5,0 m³operário/dia preconizado por Rocha (2002) para serrarias designadas como "comuns".

Biasi (2005) estudou a eficiência no desdobro de três espécies tropicais em uma serraria localizada em Sinop, MT, e obteve médias de 0,55 m³/operário/dia para a espécie cedrinho, $0,48 \mathrm{~m}^{3} /$ operário/dia para a espécie cambará e $0,44 \mathrm{~m} 3 /$ operário/dia para a espécie itaúba. Embora a eficiência média da serraria estudada tenha sido baixa, ainda assim foi superior à de uma serraria que processa madeira nativa. Esse resultado demonstra o efeito da espécie, principalmente o manuseio e tratamento individual das toras durante o desdobro, na eficiência operacional das serrarias. Ou seja, as toras de florestas tropicais são mais difíceis de manusear, por causa das grandes dimensões (diâmetro e comprimento) e incidência de defeitos (conicidade, tortuosidade e podridão) e, via de regra, das maiores densidades, resultando em maior esforço de corte. Por causa da heterogeneidade nas dimensões e volume, cada tora recebe um tratamento individual, 
sendo necessário adaptar o maquinário e o modelo de corte durante o desdobro, para se ter um melhor aproveitamento da respectiva tora, aumentando o tempo dessa operação.

\section{Amostragem do trabalho}

A amostragem piloto, realizada durante o turno 1 (período da manhã do primeiro dia), revelou que, das 120 observações, $87(\mathrm{P}=0,725)$ foram classificadas como trabalho produtivo, ao passo que as demais $(\mathrm{P}=0,275)$ foram classificadas como tempo perdido. Foram analisadas todas as máquinas da linha de produção e todos os nove operários.

Conforme a amostragem piloto, a proporção de trabalho produtivo foi igual a 0,725 ou $72,5 \%$ e, dessa forma, com $95 \%$ de certeza e exatidão de $\pm 4 \%$, o número real mínimo de amostras $(\mathrm{N})$ para a serraria foi igual a 473. Considerando o levantamento feito na amostragem piloto (turno 1) e em mais quatro turnos consecutivos, foram avaliadas 650 amostras no total (120 observações da amostragem piloto mais 530 observações posteriores), número superior às 473 determinadas inicialmente, o que aumentou a confiabilidade estatística da amostragem, uma vez que o erro recalculado diminuiu para $\pm 3,4 \%$.

Entre as atividades realizadas, foram operações classificadas como trabalho não produtivo: bitolamento, regulagem dos volantes e a guia da serra de fita, troca de lâminas, recuo morto do carro porta-toras, movimentação das toras, lubrificação da guia e conserto das garras. Como tempo ocioso, foram observados atrasos no abastecimento pela ausência de toras na rampa, parada na linha pela falta de energia elétrica e necessidades pessoais dos operadores. As demoras foram configuradas pelas seguintes atividades: empilhamento da madeira serrada, remoção dos subprodutos da linha de produção, limpeza do fosso e das caixas coletoras de serragem da máquina primária, manuseio das toras na rampa e carregamento de caminhão.

As atividades classificadas como tempo perdido foram semelhantes às observadas por Abreu et al. (2005), Batista e Carvalho (2007) e Batista et al. (2013). Porém as diferenças observadas são resultado das condições estruturais das linhas de produção, conservação e qualidade dos equipamentos e prática de manutenção preventiva, situações características de cada serraria. Na figura 3 encontra-se a análise geral da distribuição do trabalho da serraria, de acordo com o turno estudado.

Observa-se que o trabalho produtivo foi predominante em relação às demais atividades, no qual a média da serraria foi igual $69,6 \%$, superior aos $54,0 \%$ observados por Batista e Carvalho (2007). Porém o resultado foi inferior aos 90,0 e 77,1\% de trabalho produtivo observados por Abreu et al. (2005) e Batista et al. (2013), respectivamente. Essas diferenças estão relacionadas ao nível de automação, maquinários utilizados, condução da produção e comportamento da mão de obra, distintos entre as serrarias avaliadas.

Ainda na figura 3 , pode-se observar que os maiores índices de trabalho produtivo foram registrados no turno 2 (73,3\%), no período da tarde. Nesse turno não foram registradas atividades de tempo ocioso, como necessidades pessoais dos operadores, em períodos de até duas horas após os intervalos de almoço e lanche, e também houve uma queda no índice de defeitos nos maquinários em relação aos outros turnos.

Segundo Stevenson (2001), a frequência, a duração e o período de ocorrência dos intervalos podem ter um impacto significativo na disposição para o trabalho dos operários, na produtividade e na qualidade da produção. De acordo com o mesmo autor, a eficácia do trabalhador geralmente declina ao longo do dia, mas os intervalos para almoço e descanso podem causar um posterior aumento dessa variável. Nesse sentido, Barnes (1977) descreveu que os períodos de descanso são desejáveis, pois aumentam a quantidade diária de trabalho produtivo, reduzem a variabilidade na quantidade produzida, encorajam os operários a manter um nível de execução próximo da produção máxima e reduzem a fadiga física e o tempo perdido por necessidades pessoais durante as horas de trabalho.

O valor mínimo ideal de trabalho produtivo das indústrias é de $75 \%$, considerando as tolerâncias para tempo perdido (necessidades pessoais, alívio da fadiga dos trabalhadores e outros) em torno de $25 \%$ (MARTINS; LAUGENI, 2005). Nesse contexto, o trabalho produtivo médio $(69,6 \%)$ da serraria foi inferior a esse limite. Esse resultado, bem como a baixa eficiência operacional $(2,77 \mathrm{~m} 3 /$ operário/dia), pode ser explicado pelo baixo nível de mecanização e automação, falhas no gerenciamento da produção, inadequações no layout da linha de produção, obsolescência dos equipamentos, falta de manutenção preventiva, interrupção não programada do abastecimento de energia elétrica e de toras (o que causa tempo perdido e improdutividade, por causa das pausas nas operações) e falta de classificação das toras.

FLORESTA, Curitiba, PR, v. 45, n. 3, p. 487 - 496, jul. / set. 2015.

Batista, D. C. et al.

ISSN eletrônico 1982-4688 / ISSN impresso 0015-3826

493

DOI: $10.5380 /$ rf.v45i3.34441 


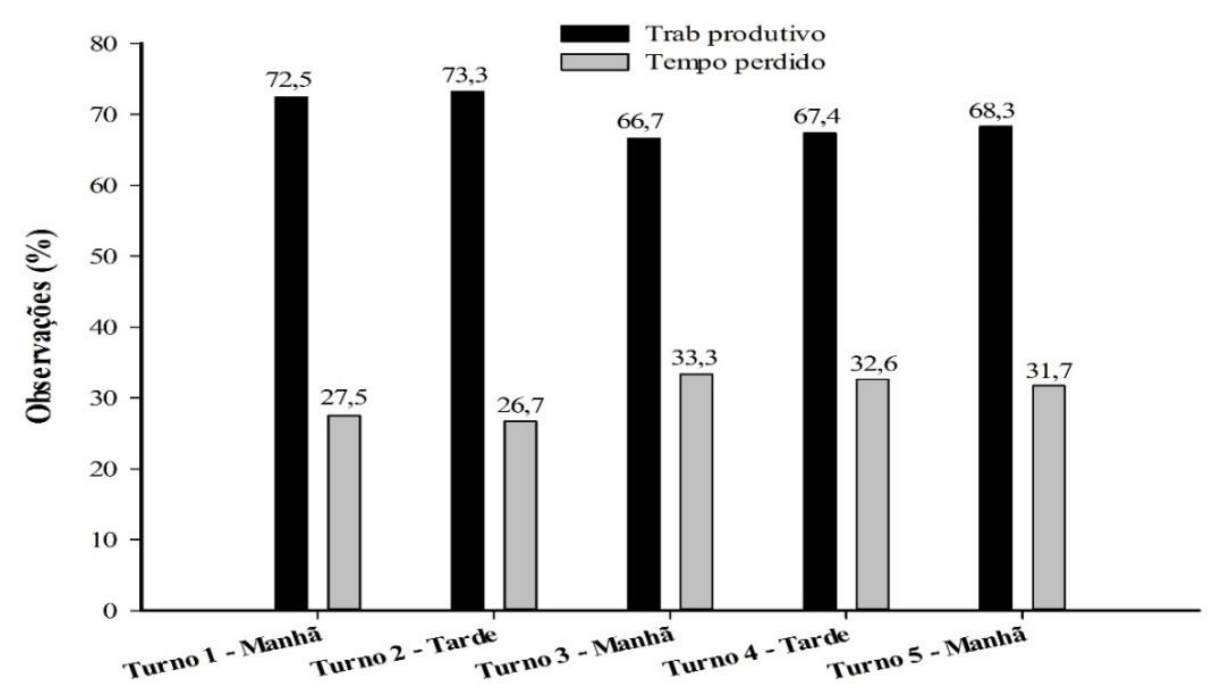

Figura 3. Análise geral da distribuição do trabalho de acordo com o turno.

Figure 3. General analysis of work distribution according to the shift.

Para que a serraria aumente o percentual de trabalho produtivo, foram feitas as seguintes recomendações: a) emprego de um trator carregador ou empilhadeira na operação de movimentação das toras e carregamento de caminhão, o que reduziria o tempo perdido e possibilitaria maior segurança e ergonomia no trabalho dos operários; b) implantação de um sistema de exaustão dos subprodutos para limpeza do fosso de serragem da serra de fita e das caixas coletoras de pó das serras circulares, diminuindose as demoras na produção; c) implantação de sistemas de movimentação da madeira serrada e melhorias no layout da linha de produção, para tornar mais rápido e prático o deslocamento das peças de madeira durante o desdobro; d) emprego ou reposicionamento de um operário para fazer o empilhamento da madeira e assim reduzir as demoras; e e) manutenção preventiva e regular, direcionada às avarias mais frequentes observadas no maquinário, como forma de minimizar a perda de tempo durante os turnos.

Para adotar as recomendações de auxílio de trator carregador, implantação de sistema de exaustão e movimentação, melhorias no layout e aumento do número de operários na linha de produção, deve ser realizado um estudo da relação custo-benefício, pois, para a sua efetivação, será necessária a realização de investimentos pela empresa.

\section{CONCLUSÕES}

- O rendimento em madeira serrada está dentro da amplitude considerada normal pela literatura especializada e correspondeu à média de aproveitamento esperada para o produto avaliado, em virtude das suas dimensões e modelo de corte adotado.

- A eficiência operacional da serraria foi baixa, em consequência de inadequações no layout da linha de produção, heterogeneidade da matéria-prima, falta de manutenção preventiva e obsolescência do maquinário, falha no abastecimento de matéria-prima e de energia elétrica e, ainda, baixo grau de mecanização e automação da serraria.

- O trabalho produtivo da serraria não atingiu o mínimo estabelecido pela literatura, o que foi decorrente de problemas na linha de produção e deficiência tecnológica.

- A situação operacional da serraria, de acordo com os índices avaliados, pode ser considerada ruim, mas possui potencial para ser melhorada, desde que sejam adotadas as recomendações feitas.

\section{REFERÊNCIAS}

ABREU, F. A.; LATORRACA, J. V. F.; CARVALHO, A. M. Eficiência operacional de serra fita: estudo de caso em duas serrarias no município de Paragominas, PA. Floresta e Ambiente, Seropédica, v. 12, n. 1, p. $44-49,2005$. 
ASSOCIAÇÃO BRASILEIRA DE NORMAS TÉCNICAS (ABNT). NBR 14807: Peças de madeira serrada - Dimensões. Rio de Janeiro, 2002.

BARNES, R. M. Estudo de movimentos e de tempos: projeto e medida do trabalho. São Paulo: Edgar Blucher, 1977, $744 \mathrm{p}$.

BATISTA, D. C.; CARVALHO, A. M. Avaliação do desempenho operacional de uma serraria através de estudo de tempo, rendimento e eficiência. Scientia Forestalis, Piracicaba, n. 75, p. 31 - 38, 2007.

BATISTA, D. C.; SILVA, J. G. M.; CORTELETTI, R. B. Desempenho de uma serraria com base na eficiência e na amostragem do trabalho. Floresta e Ambiente, Seropédica, v. 20, n. 2, p. 271 - 280, 2013.

BIASI, C. P. Rendimento e eficiência no desdobro de três espécies tropicais. 2005. 61 f. Dissertação (Mestrado em Engenharia Florestal - Tecnologia e Utilização de Produtos Florestais) - Universidade Federal do Paraná, Curitiba, 2005.

CENTRO DE DESENVOLVIMENTO DO AGRONEGÓCIO (CEDAGRO). Dimensionamento do Mercado Capixaba de Produtos Florestais Madeiráveis. Vitória, 2011. Disponível em: <http://www.cedagro.org.br/agronews/201112-vfinal/final.pdf >. Acesso em: 19/10/2014.

LATORRACA, J. V. F. Processamento mecânico da madeira. Seropédica: Universidade Federal Rural do Rio de Janeiro, 2004. 116 p.

MARTINS, P. G.; LAUGENI, F. P. Administração da produção. São Paulo: Saraiva, 2. ed. 2005.

NORDSTROM, J. A. A amostragem de trabalho. Revista de Administração de Empresas, São Paulo, v. 2, n. 3, p. 29-42, 1962. Disponível em: <http://rae.fgv.br/sites/rae.fgv.br/files/artigos/10.1590_S003475901962000300003.pdf>. Acesso em: 20/06/ 2013.

ROCHA, M. P. Eucalyptus grandis Hill ex Maiden e Eucalyptus dunnii Maiden como fontes de matéria-prima para serrarias. 2000. 186 f. Tese (Doutorado em Engenharia Florestal - Tecnologia e Utilização de Produtos Florestais) - Universidade Federal do Paraná, Curitiba, 2000. 2002. $121 \mathrm{p}$.

Técnicas e planejamento de serrarias. Curitiba: Fundação de Pesquisas Florestais do Paraná,

SCANAVACA JÚNIOR, L.; GARCIA, J. N. Rendimento em madeira serrada de Eucalyptus urophylla. Scientia Forestalis, Piracicaba, n. 63, p. 32 - 43, 2003.

SOUZA, A. N.; OLIVEIRA, A. D.; SCOLFORO, J. R. S.; MELlO, J. M.; CARVALHO, L. M. T. Modelagem do rendimento no desdobro de toras de eucalipto cultivado em sistema agroflorestal. Cerne, Lavras, v. 13, n. 2, p. 222 - 238, 2007.

STEVENSON, W. J. Administração das operações de produção. Rio de Janeiro: Livros Técnicos e Científicos, 2001, $701 \mathrm{p}$.

FLORESTA, Curitiba, PR, v. 45, n. 3, p. 487 - 496, jul. / set. 2015. 
FLORESTA, Curitiba, PR, v. 45, n. 3, p. 487 - 496, jul. / set. 2015 Batista, D. C. et al. 